\title{
Upregulation of cardiac NOS due to endotoxemia and vagal overactivity contribute to the hypotensive effect of chronic ethanol in female rats
}

\author{
Mahmoud M. El-Mas, Ming Fan, and Abdel A. Abdel-Rahman \\ Department of Pharmacology, School of Medicine, East Carolina University, Greenville, North \\ Carolina, U.S.A
}

\begin{abstract}
We previously reported that chronic ethanol lowers blood pressure in female rats. In this study, hemodynamic, biochemical, and immunoblot analyses were performed to investigate: (i) the roles of cardiac contractility and autonomic activity in the hypotensive action of ethanol, and (ii) whether endotoxemia-induced upregulation of cardiac and/or vascular nitric oxide synthase (NOS) isoforms underlies the hypotensive and cardiac effects of ethanol. Telemetric monitoring of blood pressure, heart rate, and myocardial contractility $\left(\mathrm{dP} / \mathrm{dt}_{\max }\right)$ was performed in female rats receiving liquid diet with or without ethanol (5\% w/v, 13 weeks). Autonomic control was assessed by frequency domain analysis of interbeat intervals (IBI) and systolic blood pressure (SBP).

Compared with pair-fed controls, ethanol caused sustained reductions in blood pressure, heart rate, and $+\mathrm{dP} / \mathrm{dt}_{\max }$. Ethanol feeding increased the spectral power of high-frequency band $\left(\mathrm{IBI}_{\mathrm{HF}}, 0.75\right.$ $3 \mathrm{~Hz})$ and decreased the low-frequency band $\left(\mathrm{IBI}_{\mathrm{LF}}, 0.25-0.75 \mathrm{~Hz}\right)$ and $\mathrm{IBI}_{\mathrm{LF} / \mathrm{HF}}$ ratio, suggesting increased cardiac parasympathetic dominance. In contrast, vascular tone was not affected by ethanol because SBP spectral bands and plasma norepinephrine remained unchanged. Myocardial expressions of eNOS and its upstream regulators, phosphatidylinositol 3-kinase(PI3K) and Akt, and plasma endotoxin and nitrite/nitrate were increased by ethanol. Myocardial iNOS was also increased by ethanol whereas nNOS remained unchanged and aortic levels of all NOS isoforms were not altered by ethanol. These findings suggest that facilitation of myocardial PI3K/Akt/eNOS and iNOS pathways, due possibly to ethanol-induced endotoxemia and/or increased cardiac parasympathetic dominance, might constitute a cellular mechanism for the reduced myocardial contractility and hypotension caused by ethanol in female rats.
\end{abstract}

\section{Keywords}

Ethanol; blood pressure; myocardial contractility; female rats; nitric oxide synthase; hemodynamic variability

\footnotetext{
Author for correspondence: Abdel A. Abdel-Rahman, Ph.D., Department of Pharmacology, School of Medicine, East Carolina University, Greenville, NC 27834. Tel. (252) 744-3470; Fax (252) 744-3203; abdelrahmana@ecu.edu.

Dr. M. M. El-Mas is on a sabbatical leave from the department of Pharmacology, Faculty of Pharmacy, University of Alexandria, Egypt (mahelm@hotmail.com).

Publisher's Disclaimer: This is a PDF file of an unedited manuscript that has been accepted for publication. As a service to our customers we are providing this early version of the manuscript. The manuscript will undergo copyediting, typesetting, and review of the resulting proof before it is published in its final citable form. Please note that during the production process errors may be discovered which could affect the content, and all legal disclaimers that apply to the journal pertain.
} 


\section{Introduction}

The effect of ethanol on blood pressure follows a J-shaped relationship depending on the duration and amount of ethanol consumption (Klatsky et al., 1977). Experimental reports from our laboratory showed that acute ethanol administration lowers cardiac output and subsequently blood pressure in female normotensive rats (El-Mas and Abdel-Rahman, 1999a, b). The hypotensive effect of ethanol is dependent on estrogen because it was abolished by ovariectomy and restored after estrogen replacement (El-Mas and AbdelRahman, 1999a). Ethanol lowers blood pressure in young but not in older women (Klatsky, 1990), which may highlight a role for ovarian hormones in the ethanol-blood pressure interaction. Based on the observation that ethanol increases plasma endotoxin (Rivera et al., 1998), which enhances iNOS expression and causes myocardial depression and hypotension(Thiemermann, 1997; Forstermann et al., 1998), we tested in a more recent study the hypothesis that endotoxemia-induced upregulation of cardiac iNOS mediates the hemodynamic actions of acute ethanol in female rats (El-Mas et al., 2008). Interestingly, the results showed that the hypotensive effect of ethanol was associated with significant increases in plasma endotoxin and nitrite/nitrate levels as well as myocardial iNOS contents. Further, pharmacological interventions that inhibit endogenous endotoxin (ampicillin) or iNOS (1400W) (i) abrogated the reductions in cardiac output and blood pressure caused by ethanol, and (ii) substantially reduced the ethanol-evoked increases in plasma endotoxin and nitrite/nitrate and myocardial iNOS (El-Mas et al., 2008). These findings implicated endotoxin-myocardial iNOS signaling in the reductions in cardiac output and blood pressure caused by acute ethanol in female rats (El-Mas et al., 2008).

Similar to its acute effects, a hypotensive response was also demonstrated in female rats treated chronically with ethanol (El-Mas and Abdel-Rahman, 2000, 2001). Importantly, the dose of ethanol used in these latter studies produced blood ethanol concentrations comparable to those attained in humans following consumption of moderate to intoxicating amounts of ethanol (Potter and Beevers, 1984; Abdel-Rahman et al., 1987), which established the clinical relevance of our findings. Although the hypotensive effect of chronically administered ethanol in female rats has been documented (El-Mas and AbdelRahman, 2000, 2001), the underlying mechanisms have not been identified. In this study, we tested the hypothesis that alterations of the cardiovascular autonomic control (spectral analysis of hemodynamic variability) and NOS expression in the heart underlie the reduction in $+\mathrm{dP} / \mathrm{dt}_{\max }$ (index of myocardial contractility) and the subsequent hypotensive response elicited by chronic ethanol in telemetered female rats. The potential link between chronic ethanol and enhanced myocardial iNOS expression is based on our previous findings that the acute hypotensive effect of ethanol is causally related to endotoxemia and accompanied facilitation of myocardial iNOS signaling (El-Mas et al., 2008). We also investigated the possibility that upregulation of constitutive NOS isoforms (eNOS and/or nNOS) in the myocardium contribute to the chronic hemodynamic actions of ethanol because (i) constitutively-derived NO modulates cardiac vagal (Herring and Paterson, 2001) and adrenergic (Heaton et al., 2005) neurotransmission, and (ii) the activity of constitutive NOS is upregulated by ethanol in the central nervous system and cultured endothelial cells (Venkov et al., 1999; Xia et al., 1999) and by endotoxemia (Szabo et al., 1993).

\section{Materials and Methods}

Female Sprague-Dawley rats (9-10 weeks; 190-225 g; Harlan, Indianapolis, IN) were used in the present study. Upon arrival, rats were housed individually in standard plastic cages and allowed free access to water and Purina chow and were maintained on a 12-12-h lightdark cycle with light off at 4:00 p.m. Room temperature was maintained at $22 \pm 1^{\circ} \mathrm{C}$. After 1 week acclimatization, rats were fed a standard Lieber-DiCarli high protein liquid diet (Dyets 
Inc., Bethlehem, PA) for another week before implantation of the telemetry device. Rats received the diet daily before the start of the dark cycle at 3:30 p.m. All experiments were approved by the institutional animal care and use committee and carried out in accordance with the Declaration of Helsinki and with the Guide for the Care and Use of Laboratory Animals as adopted and promulgated by the U.S. National Institutes of Health.

\subsection{Telemetry transmitter implantation}

The description of the telemetry system (Data Sciences Int., St. Paul, MN) and the method used for the telemetry transmitter implantation are detailed in our previous studies (El-Mas and Abdel-Rahman, 2000, 2001). Briefly, rats were anesthetized with i.p injection of a mixture of ketamine $(90 \mathrm{mg} / \mathrm{kg}$; Ketaject) and xylazine $(10 \mathrm{mg} / \mathrm{kg}$; Xyla-ject). The abdomen was opened with a midline incision $(4 \mathrm{~cm})$. Another incision $(1.5 \mathrm{~cm})$ was made along the inner thigh to expose the femoral artery. The abdominal wall was pierced with a needle (15 gauge) from the femoral side into the peritoneal cavity. The implant body was placed in the peritoneal cavity and the catheter $(15 \mathrm{~cm})$ was passed caudally through the syringe needle into the thigh area. A 5-cm portion of the catheter was inserted into the femoral artery and secured in place with sutures. Each rat received a subcutaneous injection of the analgesic ketorolac tromethamine $(2 \mathrm{mg} / \mathrm{kg}$; Toradol $)$ and an intramuscular injection of $60,000 \mathrm{U}$ of penicillin $\mathrm{G}$ benzathine and penicillin $\mathrm{G}$ procaine in an aqueous suspension (Durapen).

\subsection{Western blotting}

Tissues (ventricles or aortas) were homogenized on ice in a homogenization buffer [ $50 \mathrm{mM}$ Tris (pH 7.5), $0.1 \mathrm{mM}$ EGTA, $0.1 \mathrm{mM}$ EDTA, $2 \mu \mathrm{M}$ leupeptin, $1 \mathrm{mM}$ phenylmethylsulfonyl fluoride, $0.1 \%$ (vol $/ \mathrm{vol}$ ) Nonidet P-40, $0.1 \%$ SDS, and $0.1 \%$ deoxycholate]. After centrifugation $(12,000 \mathrm{~g}$ for $10 \mathrm{~min}$ ), protein in the supernatant was quantified (Bio-Rad protein assay system). Protein extracts (50 $\mu \mathrm{g}$ per lane) were run on a 4-12\% SDS-PAGE gel (Invitrogen, CA) and electroblotted to nitrocellulose membranes. Blots were blocked for $120 \mathrm{~min}$ at room temperature in rinse buffer $(10 \mathrm{mM}$ Tris, $150 \mathrm{mM} \mathrm{NaCl}, 350 \mathrm{mM}$ EDTA, $0.1 \%$ Triton X-100) containing 5\% non-fat milk. They were then incubated overnight at $4{ }^{\circ} \mathrm{C}$ in rinse buffer containing $5 \%$ non-fat milk with mouse antibody to iNOS $(1: 5,000)$, eNOS $(1: 2,500)$, nNOS (1:250) (BD Biosciences, San Jose, CA), or rabbit antibody to PI3K $(1: 1,000)$ or Akt $(1: 1,000)$ (Cell Signaling Technology ${ }^{\circledR}$, Inc. Danvers, MA). After 3 washes with rinse buffer, the blots were incubated for $60 \mathrm{~min}$ at room temperature with a goat antimouse IgG HRP conjugated secondary antibody (Bio-Rad, CA). After 3 washes with the rinse buffer, the blots were detected by enhanced chemiluminescence system and exposed to an X-ray film. Equivalent sample loading was confirmed by stripping membranes with blot restore membrane rejuvenation solution (SignaGen Laboratories, MD) and reprobing with anti-actin antibody (Sigma). Positive controls for iNOS, eNOS, nNOS (BD Biosciences, San Jose, CA), PI3K, Akt (Cell Signaling Technology ${ }^{\circledR}$, Inc. Danvers, MA) and actin (Sigma) were also loaded. Protein bands were quantified by measuring the integrated density (mean density $\times$ area) using the NIH Image software (version 1.62). Data was normalized in relation to actin, and expressed as a percent of control values as in our previous studies (Wang and Abdel-Rahman, 2002; El-Mas et al., 2008).

\subsection{Blood analyses}

Plasma estrogen (radioimmunoassay, Diagnostic Systems Laboratories, Inc., Webster, TX), norepinephrine (radioimmunoassay, ALPCO Diagnostics, Windham, NH), ethanol (enzymatic method), and NOx (fluorometric assay, Cayman Chemical Company, Ann Arbor, MI) were determined as described in our previous studies (El-Mas and AbdelRahman, 2000, 2001, 2007b; El-Mas et al., 2008). Endotoxin was measured kinetically using a chromogenic test based on the limulus amebocyte lysate (LAL) assay (Kinetic-QCL, 
BioWhittaker, Walkersville, MD) as described in our previous studies and others (Rivera et al., 1998; El-Mas et al., 2008).

\subsection{Protocols and experimental groups}

Two groups of telemetered female rats matched for body weight were used. Two weeks after telemetry transmitter implantation, one group $(n=7)$ received ethanol as described below and the other group $(\mathrm{n}=6)$ served as controls. Rats in the ethanol group were provided a standard Lieber-DeCarli high protein liquid diet containing 5\% w/v ethanol (36\% of total caloric intake) as in our previous studies (El-Mas and Abdel-Rahman, 2000, 2001). The other group of rats (controls) was pair-fed and received isocaloric amount of dextrin/maltose (89.6 g/l) in place of ethanol. To acclimate rats to the ethanol diet, ethanol (Midwest Grain Products Co., Weston, MO) was first provided as half strength $(2.5 \% \mathrm{w} / \mathrm{v}, 18 \%$ of calories intake) and then increased to $5 \% \mathrm{w} / \mathrm{v}$ after 3 days. The daily ethanol intake amounted approximately to $8-9 \mathrm{~g} / \mathrm{kg}$ body weight. Control rats were pair-fed and received isocaloric amount of dextrin/ maltose $(89.6 \mathrm{~g} / \mathrm{l})$, which allowed similar nutrient intake and fluid consumption to that of ethanol fed rats as in our previous studies (El-Mas and Abdel-Rahman, 2000, 2001). Fresh diets were prepared every other day and stored in the refrigerator until dispensed. Rats were maintained on the ethanol or control diet for 13 weeks.

Blood samples were withdrawn from the tail vein of all rats every other week for the determination of plasma estrogen, norepinephrine, ethanol, and NOx. Plasma samples were stored at $-80^{\circ} \mathrm{C}$ till analyzed. At the conclusion of the study (week 13), rats were anesthetized with pentobarbital sodium $(50 \mathrm{mg} / \mathrm{kg}$ ) and heparinized blood was collected from the portal vein using strict pyrogen free techniques for the measurement of endotoxin levels as described by others (Kono et al., 2000). Blood was centrifuged at $150 \mathrm{~g}$ for $10 \mathrm{~min}$ and the collected platelet-rich plasma was stored at $-80^{\circ} \mathrm{C}$. Rats were then euthanized with an overdose of pentobarbital sodium $(100 \mathrm{mg} / \mathrm{kg}$ ) and hearts and aortas were harvested and stored at $-80^{\circ} \mathrm{C}$ for protein analyses.

\subsection{Telemetry data acquisition and analysis}

Individual rat cages were placed on the top of the radio receivers and data were collected using a computerized data acquisition system (Dataquest A.R.T. 4.0, Data Sciences Int.). Hemodynamic measurements (MAP and heart rate) started immediately after transmitter implantation to ensure proper operation of the system. Blood pressure waveforms were sampled at a rate of $1000 \mathrm{~Hz}$ for $20 \mathrm{~s}$ every $10 \mathrm{~min}$. IBI was calculated from blood pressure waveforms. The maximum rate of rise of blood pressure waves $(+\mathrm{dP} / \mathrm{dt} \max )$, index of myocardial contractility (El-Mas and Abdel-Rahman, 2007a, b), was computed by Data Sciences software. All parameters were averaged over a 7-day period for weekly values as in our previous studies (El-Mas and Abdel-Rahman, 2000, 2001). The locomotor activity of rats was averaged during weeks 6 and 12 .

\subsection{Spectral analysis of hemodynamic variability}

Spectral hemodynamic fluctuations, quantitative indices of cardiovascular autonomic control (Stein et al., 1994; El-Mas and Abdel-Rahman, 2007a, b), were used to reflect changes in sympathetic and vagal outflows. Hemodynamic variability was assessed by the frequency domain analysis of systolic blood pressure (SBP) and interbeat interval (IBI) data series as in previous studies including our own (Clifford and Tarassenko, 2004; El-Mas and AbdelRahman, 2007a, b). Data Sciences software (Dataquest A.R.T. 4.0) uses the periodogram function of the rectangular window for direct transformation of data points into power spectral density graphs. Data were interpolated to obtain equally spaced samples with an effective sampling frequency of $10 \mathrm{~Hz}(0.1 \mathrm{~s})$. A second-order quadratic was employed to fit a smooth curve to the existing data points and produce a smoother visual representation of 
data. Spectra were integrated into 2 specific frequency bands, LF $(0.25-0.75 \mathrm{~Hz})$ and HF $(0.75-3 \mathrm{~Hz})$ bands and expressed in normalized units $\left(\mathrm{LF}_{\mathrm{nu}}\right.$ and $\left.\mathrm{HF}_{\mathrm{nu}}\right)$. The ratio of $\mathrm{LF}$ to $\mathrm{HF}\left(\mathrm{IBI}_{\mathrm{LF} / \mathrm{HF}}\right)$ is a measure of the sympathovagal balance of the heart. Parameters of hemodynamic variability were averaged over a 7 -day period for weekly values as in our previous studies (El-Mas and Abdel-Rahman, 2007a, b).

\subsection{Drugs}

Ketaject (ketamine), Xyla-ject (xylazine) (Phoenix Pharmaceuticals Inc., St Joseph, MI). Toradol (ketorolac tromethamine, Abbott Labs, Chicago, IL), Durapen (Penicillin G benzathine and penicillin G procaine, Vedco Inc., Overland Park, KS), and ethanol (Midwest Grain Products Co., Weston, MO) were purchased from commercial vendors.

\subsection{Statistical analysis}

Data are expressed as means \pm S.E.M. All parameters were averaged over a 7-day period for weekly values. The repeated measures analysis of variance (ANOVA) followed by a Newman-Keuls post-hoc test was used to test for statistical significance. Probability levels less than 0.05 were considered significant.

\section{Results}

The baseline body weights of female rats in the ethanol or control liquid diet were similar (200.5 \pm 2.4 vs. $201 \pm 2.1 \mathrm{~g}$ ). At the conclusion of the study (week 13), ethanol-fed rats exhibited significantly lower body weight $(293.3 \pm 5.6 \mathrm{~g})$ compared with control rats $(311.7 \pm 4.9 \mathrm{~g})$. The two rat groups consumed similar amounts of liquid diet $(\sim 50 \mathrm{ml} /$ day $)$. The daily ethanol consumption amounted to $8-9 \mathrm{~g} / \mathrm{kg}$ body weight and plasma ethanol levels at week 13 averaged $109 \pm 4 \mathrm{mg} / \mathrm{dl}$. Ethanol was not detected in the blood of control rats.

\subsection{Hemodynamic and autonomic effects of ethanol}

The averaged weekly values of MAP, heart rate, $\mathrm{dP} / \mathrm{dt}_{\max }$, and spectral measures of cardiovascular autonomic control are illustrated in figures 1-3. Ethanol feeding caused gradual and progressive reductions in blood pressure over the duration of the study (Fig. 1A). The hypotensive response started as early as one week after ethanol feeding, reached its nadir at week 9 and continued throughout the 13-week treatment period (Fig. 1A). The reductions in MAP caused by ethanol were statistically significant when compared with corresponding time-course values in pair-fed control rats (Fig. 1A). The hypotensive effect of ethanol was associated with reductions in heart rate(Fig. 1B) and $\mathrm{dP} / \mathrm{dt}_{\max }$ (Fig. 1C). The reductions caused by ethanol in $\mathrm{dP} / \mathrm{dt}_{\max }$ were statistically significant compared with corresponding values in control rats during weeks 2-13 (Fig. 1C). Significant reductions in heart rate were evident in ethanol-fed rats starting from week 5 (Fig. 1B). The locomotor activity of ethanol and control rats measured at week $6(1.93 \pm 0.11$ and $1.87 \pm 0.22$ counts, respectively) and week 12 (1.91 \pm 0.11 and $1.72 \pm 0.10$ counts, respectively) were not statistically different.

The spectral density of IBI in the HF range $(0.75-3 \mathrm{~Hz})$ was significantly increased by ethanol compared with control values (Fig. 2A) whereas LF $(0.20-0.75 \mathrm{~Hz})$ oscillations of IBI were significantly decreased (Fig. 2B). The $\mathrm{IBI}_{\mathrm{LF} / \mathrm{HF}}$ ratio, a measure of cardiac sympathovagal balance, was significantly reduced by ethanol starting from week 3 till the end of the study (Fig. 2C). On the other hand, SBP spectra in the LF range were not affected by ethanol treatment (Fig. 3). 


\subsection{Effects of ethanol on blood analyses and myocardial NOS proteins}

Plasma NOx, measured every other week, was significantly increased by ethanol feeding compared with control values (Fig. 4A) whereas plasma estradiol (Fig. 4B) or norepinephrine (Fig. 4C) was not affected. Plasma endotoxin measured at the conclusion of the study showed approximately 4-fold increase in ethanol-fed, compared with control, female rats $(74.9 \pm 2.7$ and $22.4 \pm 1.7 \mathrm{pg} / \mathrm{ml}$, respectively, $\mathrm{p}<0.05)$.

Western blotting showed that compared with pair-fed rats, 13-week ethanol treatment caused significant increases in ventricular PI3K, Akt, eNOS, and iNOS contents (Fig. 5). The nNOS level in cardiac tissues of ethanol-fed rats was not statistically different from that of control rats (Fig. 5). Unlike ventricular tissues, the protein expressions of the 3 NOS isoforms were not affected by ethanol feeding in the aorta (data not shown).

\section{Discussion}

In this study, we report on the role of endotoxemia and related alterations in cardiac functions and NOS signaling in the hypotensive response caused by chronic ethanol in telemetered female rats. The long-term hypotension caused by ethanol feeding in female rats was associated with decreases in $\mathrm{dP} / \mathrm{dt}_{\max }, \mathrm{IBI}_{\mathrm{HF}}$ and $\mathrm{LF} / \mathrm{HF}_{\mathrm{IBI}}$ ratio and increases in IBI ${ }_{\mathrm{HF}}$. These findings suggest enhanced and depressed parasympathetic and sympathetic control of cardiac function, respectively, which underlie the bradycardia and perhaps the reductions in myocardial contractility. At the cellular level, enhanced cardiac PI3K/Akt/ eNOS, and iNOS signaling caused probably by endotoxemia contributes, at least partly, to the hypotensive and cardiac effects of ethanol because: (i) compared with pair-fed controls, plasma NOx and endotoxin levels were dramatically increased in ethanol-fed rats, and (ii) greater protein levels of PI3K, Akt, eNOS, and iNOS were demonstrated in ventricular tissues of ethanol-fed rats.

Although the hypotensive response to chronic ethanol in female rats has been established in our previous studies (El-Mas and Abdel-Rahman, 1999a, b), the underlying molecular and hemodynamic mechanisms remain largely unknown. We considered possible contribution of vascular mechanisms to ethanol-evoked hypotension because ethanol inhibits intracellular calcium influx in vascular smooth muscle (Turlapaty et al., 1979), exerts $\alpha$-adrenergic blocking like activity (Abdel-Rahman et al., 1985) and enhances the vasodilatory effect of adenosine (Rekik et al., 2002). However, the similarity in the spectral density of SBP bands in ethanol-fed rats and their controls precludes a possible role for vascular autonomic control in the chronic hypotensive action of ethanol in our model system. This notion is supported by lack of changes in vascular NOS in ethanol fed rats (data not shown). On the other hand, reported studies including ours have established a role for reduced cardiac output, stroke volume, and myocardial contractility in the acute hypotensive effect of ethanol in female rats (El-Mas and Abdel-Rahman, 1999a, b; Choudhry et al., 2005); these findings conform with the reported depressant effect of ethanol on cardiac function (Kelbaek, 1990). Therefore, we tested the hypothesis that alterations in cardiac dynamics (myocardial contractility and autonomic activity) might underlie the hypotensive action of chronic ethanol in female rats. The radiotelemetry technique adopted in the present study allowed the computation of the maximum rate of pressure rise across the blood pressure waveform $\left(+\mathrm{dP} / \mathrm{dt}_{\max }\right)$, which serves as an index of myocardial contractility (Mehta et al., 1998; ElMas and Abdel-Rahman, 2007a, b). Also, power spectral analysis of hemodynamic variability was used to assess the chronic effects of ethanol on cardiovascular autonomic control.

The results showed that $+\mathrm{dP} / \mathrm{dt}_{\max }$ and the HF power of IBI(IBI $\mathrm{HF}_{\text {) }}$ were significantly decreased and increased, respectively, by ethanol feeding. The increase in $\mathrm{IBI}_{\mathrm{HF}}$, which 
reflects cardiac vagal control (Stein et al., 1994), caused by ethanol coincided with a decrease in $\mathrm{IBI}_{\mathrm{LF}}$, a spectral measure of cardiac sympathetic activity (Stein et al., 1994; ElMas and Abdel-Rahman, 2007a), and consequently a net decrease in the $\mathrm{IBI}_{\mathrm{LF} / \mathrm{HF}}$ ratio. The latter denotes a shift in the cardiac sympathovagal balance towards parasympathetic dominance. The decrease in heart rate of ethanol-fed rats, albeit delayed in onset, is also consistent with the increase in cardiomotor vagal activity. Interestingly, comparison of data presented in figures 1 and 2 reveals virtually identical time-course profiles for the ethanol effects on blood pressure, $+\mathrm{dP} / \mathrm{dt}_{\max }$, and cardiac spectral indices, highlighting, therefore, a temporal and possibly causal relationship between changes in cardiac autonomic activity caused by chronic ethanol, on the one hand, and reduced myocardial contractility and blood pressure on the other.

The increase in cardiac NO bioavailability triggered by iNOS induction has been fundamentally linked to cardiac contractile dysfunction (Thiemermann, 1997; Forstermann et al., 1998). In myocarditis and sepsis, NO is generated predominantly due to increased iNOS expression, which causes myocyte necrosis, contractile dysfunction, and hypotension (Ungureanu-Longrois et al., 1995). In a recent study, we established a causal role for endotoxemia-induced upregulation of cardiac iNOS in the reductions caused by ethanol in blood pressure and cardiac output (El-Mas et al., 2008). In effect, endotoxemia is believed to cause early and delayed activation of cardiovascular eNOS and iNOS, respectively (Forstermann et al., 1998) and play an integral role in the chronic biological and toxicological effects of ethanol in female rats (Kono et al., 2000; Yin et al., 2000). To build on these findings, we investigated whether the acute effects of ethanol on the endotoxin level and cardiac iNOS in female rats (El-Mas et al., 2008) also manifest after long-term exposure to ethanol. Another distinct feature of the present study was that unlike our previous study, which focused on iNOS (El-Mas et al., 2008), we report on the effect of chronic ethanol on inducible as well as constitutive NOS proteins and their regulating kinases in ventricular and vascular tissues.

Compared with controls, ethanol-fed rats exhibited approximately 4-fold increases in plasma endotoxin along with significantly higher myocardial iNOS, eNOS, PI3K, and Akt. The interaction of ethanol with NOS appears to be isoform and tissue specific because: (i) the cardiac nNOS content was not altered by ethanol, and (ii) neither inducible nor constitutive NOS was affected by ethanol in aortic tissues. It is noteworthy that endotoxin was measured, as reported elsewhere (Kono et al., 2000; El-Mas et al., 2008), in blood withdrawn from the portal vein at the conclusion of the study, which circumvented measurements of endotoxin while the study was underway. The observation, however, that plasma NOx was significantly increased during the early weeks of ethanol feeding and continued thereafter might reflect a similar time-course for endotoxemia and, therefore, implicate the endotoxinNOS signaling in the hemodynamic changes observed in ethanol-fed rats. Taken together, the current hemodynamic, biochemical, and molecular data suggest a contributory role for endotoxemia-evoked enhancement of cardiac iNOS and PI3K/Akt/eNOS signaling in cardiac autonomic imbalances, which might underlie the reductions in myocardial contractility and hypotension elicited by chronic ethanol. It is important to note, however, that the relationship between the current hemodynamic and protein expression studies is purely correlational. Pharmacological studies are needed to establish a causal relationship and to ascertain the relative contribution of inducible and constitutive NOS to the hypotensive response elicited by chronic ethanol in female rats. This issue will be addressed in future studies.

It is important to comment on the role of autonomic heart modulation in ethanol hemodynamics. Given the positive relationship between sympathetic and heart activities (Malpas, 2010), the reduction by ethanol in cardiac sympathetic activity correlates well with 
the ethanol-induced falls in myocardial contractility and blood pressure in female rats. Further, because the regulatory effect of vagal supply on heart rate is widely accepted (Stein et al., 1994), it is conceivable to suggest that the enhanced vagal tone caused by ethanol underlies the bradycardic response. With regards to myocardial contractility, although early studies revealed sparse cholinergic innervation of the ventricle (Levy and Warner, 1994), subsequent immunohistochemical and Western blotting studies including our own suggested the presence of acetylcholinesterase-sensitive neurons and $\mathrm{M}_{2}$-muscarinic acetylcholine receptors in ventricular tissues (Kawano et al., 2003; Shaltout and Abdel-Rahman, 2005). Further, evidence obtained from functional studies suggests that cardiac parasympathetic activity acts directly or indirectly to negatively influence inotropic properties (Zang et al., 2005). Indeed, it has been shown that the activation of cardiac $M_{2}$ receptors attenuates the contractile response to $\beta$-adrenergic stimulation via activation of the $\mathrm{G} \alpha_{\mathrm{i} 2}$, which inhibits Ltype calcium channels and reduces intracellular calcium levels (Endoh, 1999; Nagata et al., 2000).

Although cellular mechanisms that underlie ethanol interaction with the cardiac parasympathetic component were not directly investigated in the present study, our finding that chronic ethanol feeding enhanced ventricular expression of eNOS might implicate NOS-dependent mechanism in the cardiac effect of ethanol. Because the eNOS-derived NO mediates the parasympathetic control of myocardial function (Balligand et al., 1993), it is likely that the enhanced NOS activity that follows the increase in cardiac parasympathetic activity in ethanol-fed rats might explain the depressant effect of ethanol on myocardial contractility. This view is supported by the observation that the inhibition of eNOS, which is constitutively expressed in rodent (Balligand et al., 1995), and human (Wei et al., 1996) cardiac myocytes, or its downstream effector guanylyl cyclase antagonizes the depressant effect of muscarinic agonists on myocardial contractility (Balligand et al., 1993). Similarly, NOS inhibition blocks the attenuation caused by cholinergic agonists in $\beta$-adrenoceptormediated increased in L-type calcium channel currents (Balligand et al., 1995).

In conclusion, this study is the first to report on cardiac and cellular mechanisms that might contribute to the chronic hypotensive effect of ethanol in female rats. The cascade of events involves the ability of ethanol to increase NO bioavailability, presumably due to endotoxemia-evoked upregulation of cardiac iNOS and PI3K/Akt/eNOS signaling, which apparently reduces myocardial contractility, cardiac output, and subsequently blood pressure. The altered cardiac parasympathetic (increased) and sympathetic (decreased) activity, as evidenced by power spectral analysis of heart rate variability, might also contribute to the upregulation of cardiac eNOS and possibly underlies the reductions in myocardial contractility and consequently the hypotension in ethanol-fed female rats. Notably, the 5\% ethanol concentration employed in this study produced blood levels consistent with moderate alcohol consumption in humans (Potter and Beevers, 1984; AbdelRahman et al., 1987).

\section{Acknowledgments}

Supported by Grant R01 AA014441 from the National Institute on Alcohol Abuse and Alcoholism. The authors thank Ms. Kui Sun for her technical assistance.

\section{References}

Abdel-Rahman ARA, Dar MS, Wooles WR. Effects of chronic ethanol administration on arterial baroreceptor function and pressor and depressor responsiveness in rats. J Pharmacol Exp Ther 1985;232:194-201. [PubMed: 4038417] 
Abdel-Rahman ARA, Merrill RH, Wooles WR. Effect of acute ethanol administration on the baroreceptor reflex control of heart rate in normotensive human volunteers. Clin Sci 1987;72:113122. [PubMed: 3802717]

Balligand JL, Kelly RA, Marsden PA, Smith TW, Michel T. Control of cardiac muscles cell function by an endogenous nitric oxide signaling system. Proc Natl Acad Sci USA 1993;90:347-351. [PubMed: 7678347]

Balligand JL, Kobzik L, Han X, Kaye DM, Belhassen L, O’Hara DS, Kelly RA, Smith TW, Michel T. Nitric oxide-dependent parasympathetic signaling is due to activation of constitutive endothelial (type III) nitric oxide synthase in cardiac myocytes. J Biol Chem 1995;270:14582-14586. [PubMed: 7540173]

Choudhry MA, Ba ZF, Rana SN, Bland KI, Chaudry IH. Alcohol ingestion before burn injury decreases splanchnic blood flow and oxygen delivery. Am J Physiol Heart Circ Physiol 2005;288:H716-721. [PubMed: 15388502]

Clifford GD, Tarassenko L. Segmenting cardiac-related data using sleep stages increases separation between normal subjects and apnoeic patients. Physiol Meas 2004;25:N27-35. [PubMed: 15712732]

El-Mas MM, Abdel-Rahman AA. Estrogen-dependent hypotensive effects of ethanol in conscious female rats. Alcohol Clin Exp Res 1999a;23:624-632. [PubMed: 10235298]

El-Mas MM, Abdel-Rahman AA. Sexually dimorphic hemodynamic effects of intragastric ethanol in conscious rats. Clin Exp Hypertens 1999b;21:1429-1445. [PubMed: 10574422]

El-Mas MM, Abdel-Rahman AA. Ovariectomy alters the chronic hemodynamic and sympathetic effects of ethanol in radiotelemetered female rats. Clin Exp Hypertens 2000;22:109-126. [PubMed: 10685729]

El-Mas MM, Abdel-Rahman AA. An association between the estrogen-dependent hypotensive effect of ethanol and an elevated brainstem $c$-jun mRNA in female rats. Brain Res 2001;912:79-88. [PubMed: 11520495]

El-Mas MM, Abdel-Rahman AA. Intermittent clonidine regimen abolishes tolerance to its antihypertensive effect: a spectral study. J Cardiovasc Pharmacol 2007a;49:174-181. [PubMed: 17414230]

El-Mas MM, Abdel-Rahman AA. Role of myocardial contractility and autonomic control in the hypotensive response to a limited access ethanol paradigm in SHRs. Alcohol Clin Exp Res 2007b; 31:1071-1079. [PubMed: 17428291]

El-Mas MM, Fan M, Abdel-Rahman AA. Endotoxemia-mediated facilitation of cardiac iNOS expression accounts for the hypotensive effect of ethanol in female rats. J Pharmacol Exp Ther 2008;324:368-375. [PubMed: 17925480]

El-Mas MM, Zhang J, Abdel-Rahman AA. Upregulation of vascular inducible nitric oxide synthase mediates the hypotensive effect of ethanol in conscious female rats. J Appl Physiol 2006;100:1011-1018. [PubMed: 16293701]

Endoh M. Muscarinic regulation of $\mathrm{Ca}^{2+}$ signa ling in mammalian atrial and ventricular myocardium. Eur J Pharmacol 1999;375:177-196. [PubMed: 10443574]

Forstermann U, Boissel JP, Kleinert H. Expressional control of the 'constitutive' isoforms of nitric oxide synthase (NOS I and NOS III). FASEB J 1998;12:773-790. [PubMed: 9657518]

Heaton DA, Golding S, Bradley CP, Dawson TA, Cai S, Channon KM, Paterson DJ. Targeted nNOS gene transfer into the cardiac vagus rapidly increases parasympathetic function in the pig. J Mol Cell Cardiol 2005;39:159-164. [PubMed: 15893765]

Herring N, Paterson DJ. Nitric oxide-cGMP pathway facilitates acetylcholine release and bradycardia during vagal nerve stimulation in the guinea-pig in vitro. J Physiol 2001;535:507-518. [PubMed: 11533140]

Kawano H, Okada R, Yano K. Histological study on the distribution of autonomic nerves in the human heart. Heart Vessels 2003;18:32-39. [PubMed: 12644879]

Kelbaek H. Acute effects of alcohol and food intake on cardiac performance. Prog Cardiovasc Dis 1990;32:347-364. [PubMed: 2179995]

Klatsky AL, Friedman GD, Siegelaub AB, Gerard MJ. Alcohol consumption and blood pressure. N Engl J Med 1977;296:1194-1200. [PubMed: 854058] 
Klatsky, AL. Blood pressure and alcohol intake. In: Laragh, JH.; Brenner, BM., editors. Hypertension: Pathophysiology, Diagnosis, and Management. Raven Press Ltd; 1990. p. 277-294.

Kono H, Wheeler MD, Rusyn I, Lin M, Seabra V, Rivera CA, Bradford BU, Forman DT, Thurman RG. Gender differences in early alcohol-induced liver injury: role of CD14, NF-kappaB, and TNFalpha. Am J Physiol 2000;278:G652-661.

Levy, MN.; Warner, MR. Parasympathetic effects on cardiac function. In: Armour, JA.; Ardell, JL., editors. Neurocardiology. Oxford Univ Press; New York: 1994. p. 53-76.

Malpas SC. Sympathetic nervous system overactivity and its role in the development of cardiovascular disease. Physiol Rev 2010;90:513-5157. [PubMed: 20393193]

Mehta MC, Jain AC, Billie M. Combined effects of alcohol and nicotine on cardiovascular performance in a canine model. J Cardiovasc Pharmacol 1998;31:930-936. [PubMed: 9641479]

Nagata K, Ye C, Jain M, Milstone DS, Liao R, Mortensen RM. G $\alpha_{\mathrm{i} 2}$ but not $\mathrm{G} \alpha_{\mathrm{i} 3}$ is required for muscarinic inhibition of contractility and calcium currents in adult cardiomyocytes. Circ Res 2000;87:903-909. [PubMed: 11073886]

Potter JF, Beevers F. Pressor effect of alcohol in hypertension. Lancet 1984;1:119-122. [PubMed: 6140440]

Rekik M, El-Mas MM, Mustafa SJ, Abdel-Rahman AA. Role of endothelial adenosine receptormediated vasorelaxation in ethanol-induced hypotension in hypertensive rats. Eur J Pharmacol 2002;452:205-214. [PubMed: 12354571]

Rivera CA, Bradford BU, Seabra V, Thurman RG. Role of endotoxin in the hypermetabolic state after acute ethanol exposure. Am J Physiol 1998;275:G1252-G1258. [PubMed: 9843760]

Shaltout HA, Abdel-Rahman AA. Mechanism of fatty acids induced suppression of cardiovascular reflexes in Rats. J Pharmacol Exp Ther 2005;314:1328-1337. [PubMed: 15937146]

Stein PK, Bosner MS, Kleiger RE, Conger BM. Heart rate variability: a measure of cardiac autonomic tone. Am Heart J 1994;127:1376-1381. [PubMed: 8172068]

Szabo C, Mitchell JA, Thiemermann C, Vane JR. Nitric oxide-mediated hyporeactivity to noradrenaline precedes the induction of nitric oxide synthase in endotoxin shock. Br J Pharmacol 1993;108:786-792. [PubMed: 7682137]

Thiemermann C. Nitric oxide and septic shock. Gen Pharmacol 1997;29:159-166. [PubMed: 9251894]

Turlapaty PDMV, Altura BT, Altura BM. Ethanol reduces $\mathrm{Ca}^{2+}$ concentration in arterial and venous smooth muscle. Experientia 1979;35:639-640. [PubMed: 446664]

Ungureanu-Longrois D, Balligand JL, Kelly RA, Smith TW. Myocardial contractile dysfunction in the systemic inflammatory response syndrome: role of a cytokine-inducible nitric oxide synthase in cardiac myocytes. J Mol Cell Cardiol 1995;27:155-167. [PubMed: 7539082]

Venkov CD, Myers PR, Tanner MA, Su M, Vaughan DE. Ethanol increases endothelial nitric oxide production through modulation of nitric oxide synthase expression. Thromb Haemost 1999;81:638-642. [PubMed: 10235453]

Wang X, Abdel-Rahman AA. Estrogen modulation of eNOS activity and its association with caveolin-3 and calmodulin in rat hearts. Am J Physiol 2002;282:H2309-H2315.

Wei CM, Jiang SW, Lust JA, Daly RC, McGregor CGA. Genetic expression of endothelial nitric oxide synthase in human atrial myocardium. Mayo Clin Proc 1996;71:346-350. [PubMed: 8637256]

Xia J, Simonyi A, Sun GY. Chronic ethanol and iron administration on iron content, neuronal nitric oxide synthase, and superoxide dismutase in rat cerebellum. Alcohol Clin Exp Res 1999;23:702707. [PubMed: 10235306]

Yin M, Ikejima K, Wheeler MD, Bradford BU, Seabra V, Forman DT, Sato N, Thurman RG. Estrogen is involved in early alcohol-induced liver injury in a rat enteral feeding model. Hepatology 2000;31:117-123. [PubMed: 10613736]

Zang WJ, Chen LN, Yu XJ. Progress in the study of vagal control of cardiac ventricles. Sheng Li Xue Bao 2005;57:659-672. [PubMed: 16344889] 

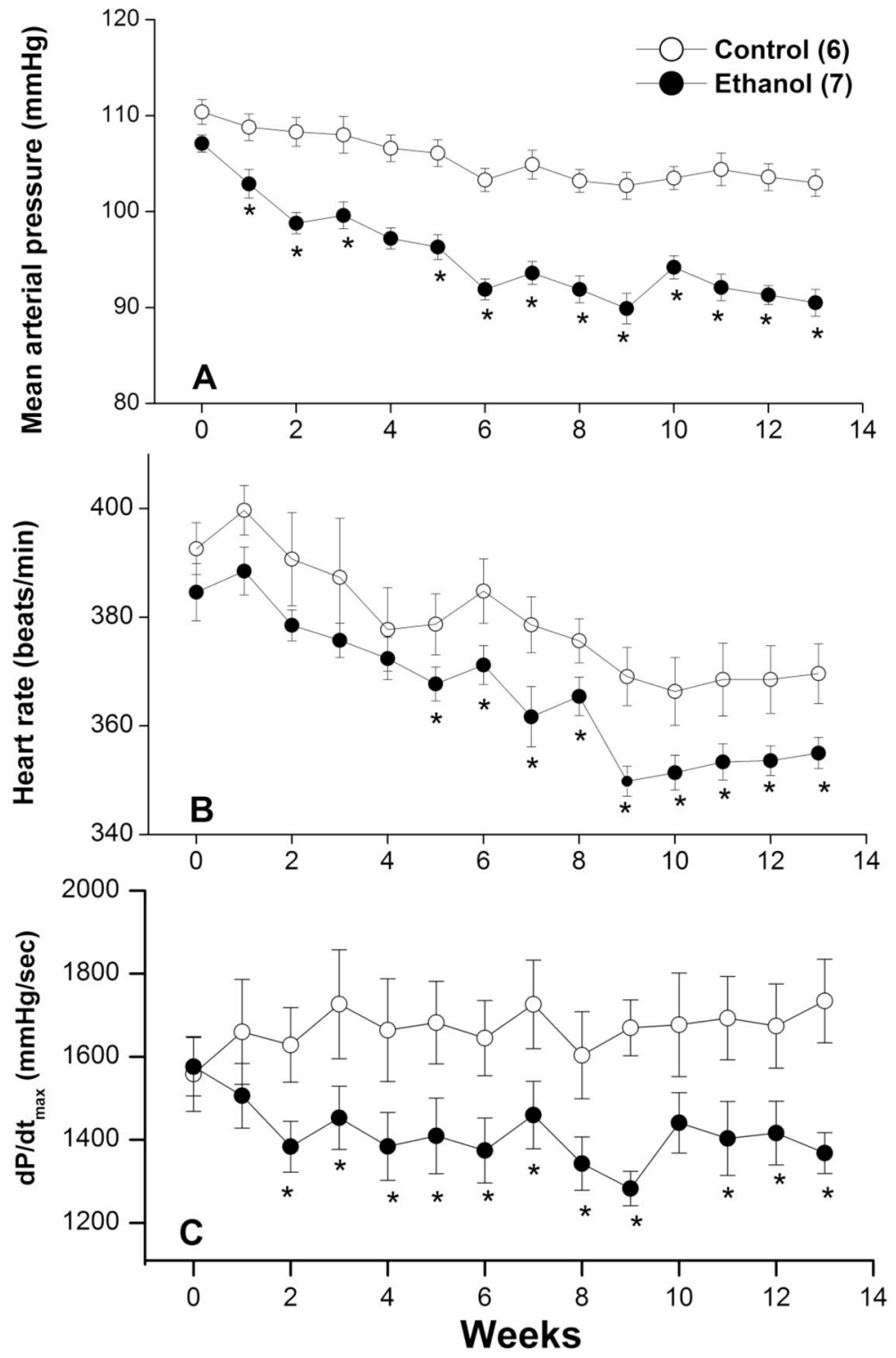

Figure 1.

Effect of chronic ethanol feeding $(5 \% \mathrm{w} / \mathrm{v})$ or isocaloric control diet on mean arterial pressure (panel A), heart rate (panel B), or myocardial contractility $\left(\mathrm{dP} / \mathrm{dt}_{\max }\right.$, panel C) in telemetered female Sprague-Dawley rats. Values are weekly means \pm S.E.M of 6-7 observations. ${ }^{*} \mathrm{P}<0.05$ versus corresponding time-course control values. 


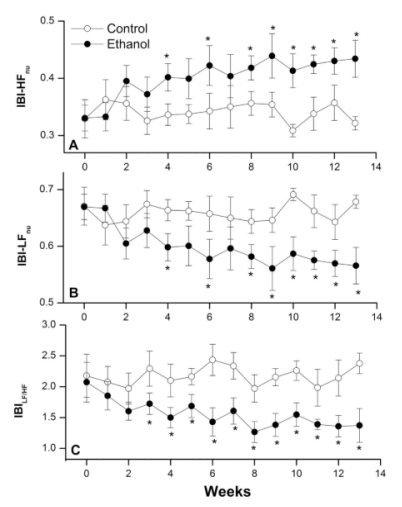

Figure 2.

Effect of chronic ethanol feeding $(5 \% \mathrm{w} / \mathrm{v})$ or isocaloric control diet on the spectral density of interbeat intervals (IBI) in the low-frequency (IBI-LF $\mathrm{Lu}_{\mathrm{nu}}, 0.25-0.75 \mathrm{~Hz}$, panel A), and high-frequency (IBI-HF ${ }_{n u}, 0.75-3 \mathrm{~Hz}$; panel B) ranges as well as on the LF/HF ratio of IBI (panel C) in telemetered female Sprague-Dawley rats. Values are weekly means S.E.M of 67 observations. ${ }^{*} \mathrm{P}<0.05$ versus corresponding time-course control values. 


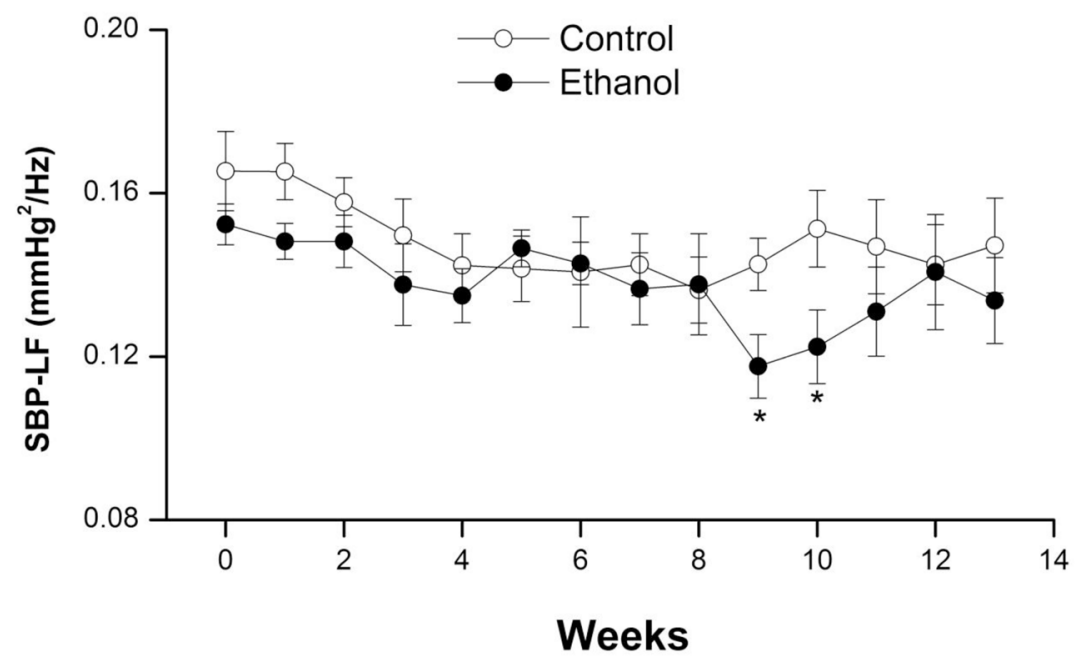

Figure 3.

Effect of chronic ethanol feeding $(5 \% \mathrm{w} / \mathrm{v})$ or isocaloric control diet on the spectral density of systolic blood pressure (SBP) in the low-frequency range (SBP-LF, 0.25-0.75 Hz) in telemetered female Sprague-Dawley rats. Values are weekly means \pm S.E.M of 6-7 observations. 

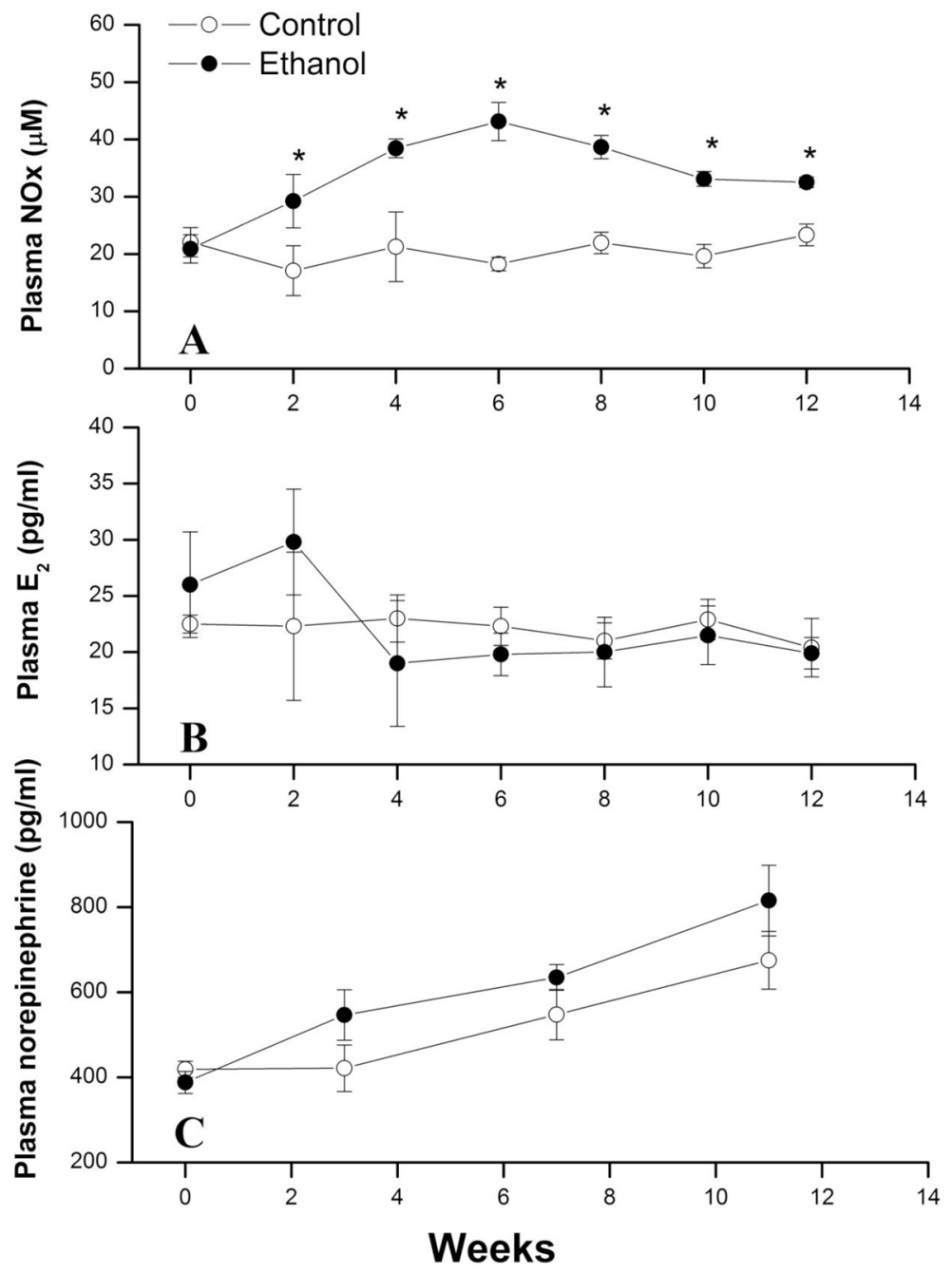

Figure 4.

Effect of chronic ethanol feeding $(5 \% \mathrm{w} / \mathrm{v})$ or isocaloric control diet on plasma levels of nitrite/nitrate (NOx, panel A), estradiol ( $E_{2}$, panel B), or norepinephrine (panel C) in telemetered female Sprague-Dawley rats. Values are means \pm S.E.M of 6-7 observations. ${ }^{*} \mathrm{P}<0.05$ versus corresponding time-course control values. 

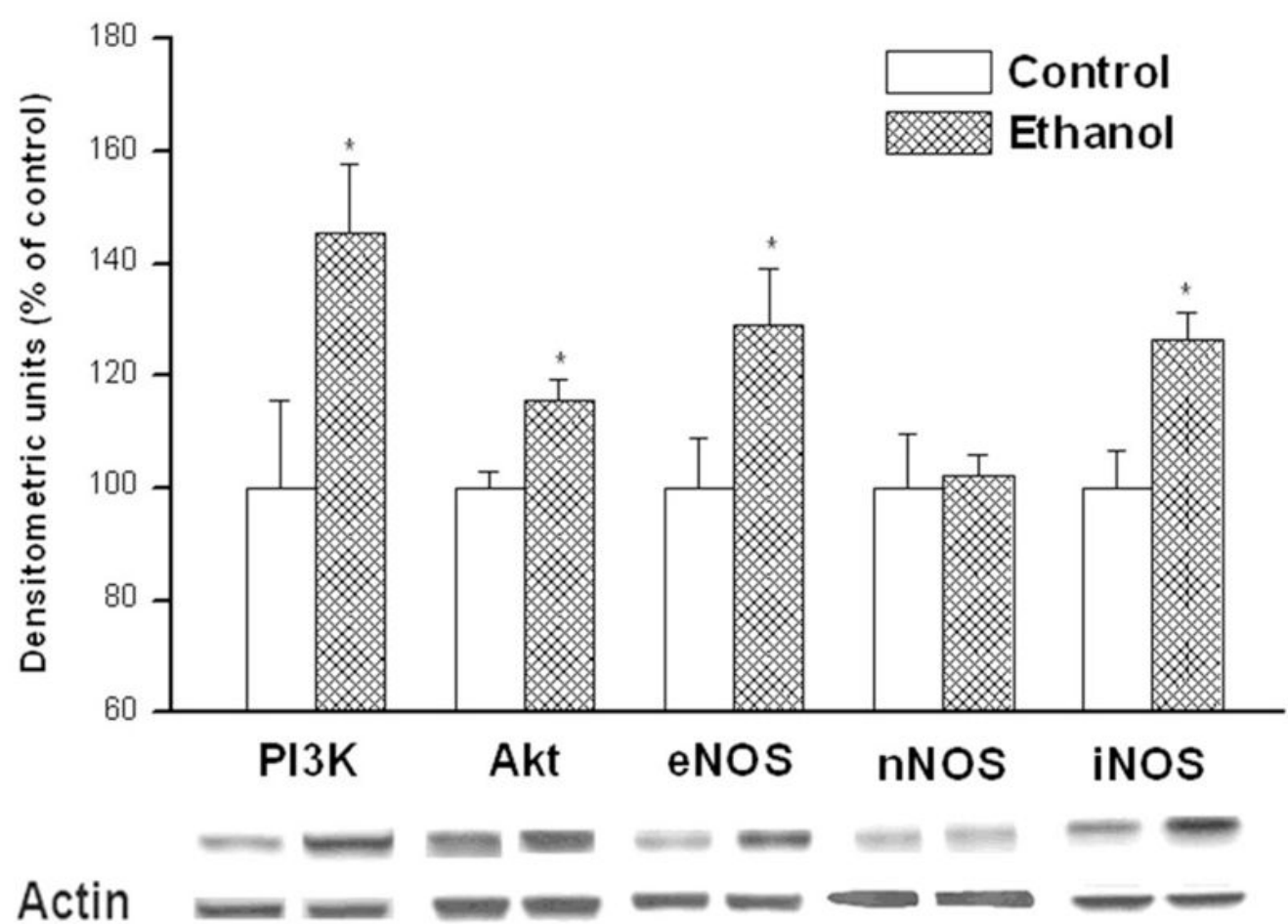

Figure 5.

The protein expression of inducible (iNOS) and constitutive (eNOS and nNOS) NOS isoforms in cardiac tissues of female Sprague-Dawley rats treated chronically with ethanol $(5 \% \mathrm{w} / \mathrm{v}, 13$ weeks) or isocaloric control diet. Illustrative gels depicting myocardial NOS protein expression are shown. Values are means \pm S.E.M of $6-7$ observations. ${ }^{*} \mathrm{P}<0.05$ versus corresponding control values. 